\title{
Dynamic Capability: an analysis in multi-unit service providers
}

\author{
Rodrigo Valio Dominguez Gonzalez ${ }^{\text {a* }}$ \\ aUniversidade de Campinas, Limeira, SP, Brasil \\ *rodrigo.gonzalez@fca.unicamp.br
}

\begin{abstract}
Paper aims: This study aims to analyze the relationship between teamwork factors and the process of dynamic capability in service providers.

Originality: Few researches seek to understand the organizational factors that promote dynamic capacity. In this sense, this research seeks to fill this gap by analyzing the development of dynamic capability from the intrinsic characteristics to teamwork.

Research method: In order to reach the research objective, a survey research was carried out in 188 service provider companies and the Partial Least Squares (PLS) was used to analyze the data.

Main findings: The results show that the cohesion, autonomy and integration of the team present high levels of positive relation with the processes of absorption, generation, storage and adaptation of knowledge.

Implications for theory and practice: The results of this study show that three characteristics that are intrinsic to teamwork (autonomy, integration and cohesion) in multi-unit service providers support the dynamic capability, in terms of the absorption, generation, storage and adaptation of knowledge.
\end{abstract}

Keywords

Knowledge. Capability. Teamwork. Multi-unit service. Structural equation modeling.

How to cite this article: Gonzalez, R. V. D. (2018). Dynamic Capability: an analysis in multi-unit service providers. Production, 28, e20180046. https://doi.org/10.1590/0103-6513.20180046.

Received: May 30, 2018; Accepted: Oct. 31, 2018.

\section{Introduction}

Competition among companies requires search for innovation in order to achieve improved productivity and competitiveness. Such innovation can be achieved by improving organizational competences, that is, through a company's dynamic capability (0'Reilly \& Tushman, 2008). Teece et al. (1997) found that leading companies are those that achieve rapid response of product and process innovation through the adoption of dynamic capabilities.

Dynamic capability can be defined as the firm's ability to integrate, build, and reconfigure internal and external competences to address rapidly changing environments (Teece et al., 1997). Then, dynamic capabilities enable firms to develop new knowledge and skills that place them in new markets (Eisenhardt \& Martin, 2000).

One reason of the great interest in dynamic capabilities is related to their power to generate competitive advantage (Zollo \& Winter, 2002; Teece et al., 1997). However, although the concept of dynamic capability was largely studied in the last decade, its practical use is still limited (Jones \& Knoppen, 2018). Most studies present two central problems. The first refers to the lack of consensus in explaining how dynamic capabilities are developed in organizations. And the second refers to the lack of agreement between the construction of dynamic capabilities and the organizational context.

Regarding the development of dynamic capabilities, this study is supported by the concept of knowledge-based dynamic capabilities. Zahra \& George (2002), when studying knowledge absorptive capacity, concluded this 
concept was inherent to the dynamic capability of the firm and, based on that, they proposed the knowledge-based dynamic capability. Based on this view and aligning it with the knowledge-based view of the firm (Teece et al., 1997), dynamic capability is considered a first-level capability that defines the performance of routines and other competences of an organization (Hitt et al., 2016).

Regarding the organizational context, this study is focused on teamwork performed in companies that provide specialized industrial services. The organizations that provide this type of service usually have a multi-unit structure, that is, they have teams working at the sites of customers operating in different industries (Gonzalez et al., 2014; Lee et al., 2015; Gonzalez, 2017).

As these service provision teams are in direct contact with customers to propose and implement solutions for performance improvement, the development of dynamic capability becomes more intense, considering the continuous need to absorb knowledge from the customers, generate knowledge from a base provided by customers and adapt knowledge to different situations and industrial customers (Wilden \& Gudergan, 2017; Gonzalez et al., 2014). A firm, in this context, has a central role as an agent of retention of knowledge absorbed, generated and adapted in different service provision points. When the service provision firm fails in its key role of knowledge repository, it loses its ability to develop dynamic capability and generate competitive advantage (Lee et al., 2015).

Teamwork can be defined as teams that have some autonomy to make decisions and organize work (Mathieu et al., 2008). In addition, the teams involved in multi-unit specialized service provision are made up of individuals with complementary competences, committed to performance goals aligned with customer needs, and inserted into an organization model that enables the flow of information and knowledge between different service provision units, with the service provision firm assuming the centralizing role in the process of knowledge retention and coordination (Salas et al., 2008; Lee et al., 2015; Wilden \& Gudergan, 2017).

The characteristics of teamwork favor the development of dynamic capabilities (Wilden \& Gudergan, 2017; Gonzalez \& Melo, 2017). Based on the definition of teamwork, aspects such as autonomy and sharing of purpose (Gonzalez, 2017), shared social context (Lee et al., 2015) and sharing of competences that favor knowledge creation and use. However, the literature has no studies that evaluate the relationship between these predominant characteristics of teamwork and dynamic capability, and this gap is more evident in the literature about service provision. Therefore, the main objective of this study is to answer the following question: How are the characteristics of teamwork related to dynamic capability in the context of multi-unit service provision?

\section{Dynamic capability}

The concept of dynamic capability is an extension of the resource-based view (RBV) of the firm, which states that the firm's resources and heterogeneity allow competitive advantages (Teece et al., 1997). Considering the changes in the environment and the challenges proposed by the competition, the RBV has been complemented by two concepts: dynamic capability and knowledge-based view (KBV) of the firm (Hitt et al., 2016; Gutierrez et al., 2018).

Unlike operational capabilities, which act on the firm's resources to produce specific results using predefined routines (Denford, 2013), dynamic capabilities act on the change and reconfiguration of operational capabilities (Teece et al., 2016; Gonzalez \& Melo, 2017).

Teece et al. (1997) used the term 'dynamic capability' to refer to the firm's ability to renew its competences over time to address changes in the business environment through integration, reconstruction and reconfiguration of functional skills, resources and competences, including them into strategic changes. Eisenhardt \& Martin (2000) define this reconfiguration from cross-functional routines, such as new product development, coordination process for internal collaboration, knowledge creation process, acquisition process and alliance.

Zollo \& Winter (2002) define dynamic capability as "a pattern of collective activity through which the organization systematically generates and modifies its operating routines in pursuit of improved effectiveness" (2002, p. 340). Then, dynamic capabilities are developed and incorporated into organizational routines, and not simply bought in the market (Jones \& Knoppen, 2018). Teece et al. (2016) highlights the firm's functional activities - those that allow its existence in the market - constitute its operational capabilities. Dynamic capabilities, in turn, allow the organization to understand its environment, the value of resources and appropriately respond to changes in the market to improve its operational capabilities. For this reason, Teece et al. (2016) calls dynamic capabilities as first-level capability.

Denford (2013) proposes that knowledge-based dynamic capability can be seen as a group of knowledge management activities that change, renew and exploit knowledge-based firm resources. Wang et al. (2007) 
highlight that, based on knowledge-based dynamic capability, the firm's competitive advantage is built through continuous adjustments and improvements in the organization's knowledge base.

Several authors have proposed constructs related to dynamic capability. According to Denford (2013) there is a lack of uniformity in the nomenclature of the constructs that make up dynamic capability, but, in general, all models proposed by the authors take into account the three dimensions mentioned above.

When evaluating the composition of some models used by different authors to address dynamic capability, Zheng et al. (2011) argue that knowledge-based dynamic capability consists of a firm's ability to acquire, generate and combine knowledge to explore and access dynamic environments. Wang et al. (2007) define dynamic capability as the absorption, creation, storage and application of knowledge. Denford (2013) identifies eight constructs related to knowledge-based dynamic capability: creation, integration, reconfiguration, replication, development, assimilation, synthesis and imitation of knowledge. Han \& Li (2015), in a survey conducted with Chinese companies and based on the proposals of Zheng et al. (2011), Denford (2013) and Wang et al. (2007), defined dynamic capability from three constructs: knowledge sensing, knowledge seizing, and knowledge reconfiguring.

Although the studies analyzed here do not present a common nomenclature, in general, the stages that constitute dynamic capability are present in all models. Also, in some studies, a specific stage includes a process that was considered separately by another author. For instance, regarding the capability to absorb external knowledge, some authors refer to this stage as acquisition capability (Zheng et al., 2011; Denford, 2013) and others call it learning capability (Gutierrez et al., 2018). The capability to create or generate knowledge internally is defined by authors such as Han \& $\mathrm{Li}(2015)$ as the capability to detect knowledge, or as learning capability, according to Han \& $\mathrm{Li}$ (2015). The stage of knowledge storage is intrinsic to the acquisition and generation stages, as proposed by Zheng et al. (2011), or the learning capability stage of Singh \& Rao (2016). The adaption capacity is considered by some authors as combinative capability (Zheng et al., 2011) or integrative capability (Singh \& Rao, 2016; Denford, 2013). According to Wang et al. (2007), the combinative capability is inserted in the stage of knowledge application, and for Han \& Li (2015), in knowledge reconfiguring.

This study uses similar nomenclature to that proposed by Wang et al. (2007): absorptive capacity, generation capability, storage capability and adaption capacity.

- Knowledge absorptive capability: first, to understand this concept, a distinction should be made between internal and external knowledge. Knowledge absorptive capacity refers to the process of acquisition, assimilation, transformation and exploitation of external knowledge (Cohen \& Levinthal, 1990). Considering knowledge has a tacit portion and an explicit portion, absorptive capacity is limited in relation to the first portion due to difficult transference and imitation (Zheng et al., 2011). Some authors, like Teece et al. (2016) and Lee (2018), emphasize that absorptive capacity must be accompanied by knowledge sensing capacity, considering such difficult absorption of tacit knowledge. In this sense, it is not enough to have access to manuals, procedures or patents. Absorptive capacity, to be complete and broad, must also be surrounded by knowledge sensing capacity, in terms of broad understanding, involving a broad base of prior knowledge (Teece et al., 2016).

- Knowledge generation capability: according to Grant (1996), organizations are knowledge repositories and, as such, they need to create new knowledge. Knowledge generation refers to a firm' ability to develop and refine activities and processes that promote the creation and generation of new knowledge (Zheng et al., 2011; Gonzalez \& Melo, 2017). The creation of new knowledge is a process that takes place internally in the firm through research and development activities and cooperative alliances between companies with common objectives (Denford, 2013). Strategic alliances allow the production of assets and competences the firm does not have through association with other companies that have specialized knowledge (Singh \& Rao, 2016). The concept of organizational learning also is strongly linked with knowledge generation capability. Learning consists of the process of exploring skills of individuals to generate new knowledge. Cohen \& Levinthal (1990) argue that learning is based on routine, as it allows individuals to construct a prior knowledge base, and new knowledge can be generated from such knowledge base, in a perspective defined as single-loop learning by Argyris \& Schön (1978). The routine can still have deeper transformations as the prior knowledge base is questioned and individuals search new knowledge using a knowledge exploration approach, or double-loop knowledge (Argyris \& Schön, 1978).

- Knowledge storage capability: the stage of knowledge storage refers to the process of organizational memory creation, in which knowledge is formally stored in physical memory systems and informally retained as values, norms and beliefs, which are associated with organizational culture and structure (Alavi \& Leidner, 2001). Walsh \& Ungson (1991, p. 61) emphasize the importance of this stage, defining organizational memory as: 'stored information from an organization's history that can be brought to bear on present decisions,' that is, stored information about the organization's history that is considered in present decisions. Alavi \& Leidner (2001) 
explains that knowledge storage includes a conversion process that involves organization, structuring, storage and, finally, combination of knowledge for easy reference in the future by users. Then, information technology (IT) appears as a key tool in this stage, offering three applications: (i) knowledge coding and sharing; (ii) the creation of corporate knowledge directories; (iii) the creation of knowledge networks (Alavi \& Leidner, 2001).

- Knowledge adaption capability: this stage refers to the firm's ability to integrate and apply internal and external knowledge to solve internal problems (Zheng et al., 2011). Authors such as Grant (1996) and Denford (2013) propose that much of the competitive advantage of organizations comes from a greater knowledge adaption capacity. An organization with superior adaption capacity will be able to use knowledge that is absorbed or generated in activities that generate new knowledge. On the other hand, lower adaption capacity leads to failure in recognizing the value of knowledge, reducing the company's innovative and creative potential.

\section{Teamwork}

A team can be considered as the smallest unit in which members of an organization work together (Shin et al., 2012). Team members share and apply common knowledge to perform tasks and achieve organizational goals and objectives.

Several models have been studied by authors to define the factors that affect different perspectives regarding team performance (Kozlowski \& llgen, 2006; Salas et al., 2008). These factors can enable or impair interaction among the various members, contributing to the learning process, and knowledge creation and sharing (Jaca et al., 2013).

A well-known model is the Input-Mediators-Output (IMO), proposed by llgen et al. (2005) and reviewed by Mathieu et al. (2008). This model presents a team organization in a clear and structured way and identifies how teams change and become mature over time as a result of the development of factors (Mathieu et al., 2008).

The studies conducted by Mathieu et al. (2008) and llgen et al. (2005) present a broad characterization of inputs that support the development of the team context. In this work, in view of the research objective related to dynamic capability, the inputs of teamwork researched are those that support the flow and sharing of knowledge between individuals and decision making: cohesion, integration and autonomy.

\section{Factors related to teamwork and hypothesis development}

Zahra \& George (2002) argue that not only the individual knowledge absorptive capacity impacts the development of dynamic capability, but also organizational mechanisms that facilitate the exchange of knowledge between individuals. They are identified by the authors as elements of social integration and refer to formal and informal mechanisms that reduce barriers to share knowledge. Several studies that address this issue divide these barriers into two categories: barriers related to the capacity to integrate knowledge and barriers related to decision making and autonomy (Lowik et al., 2016).

In this sense, studies on team context are based on these integration mechanisms. Regarding barriers related to knowledge integration, authors such as Cohen \& Levinthal (1990) highlight the lack of organizational infrastructure or communication channels that enable the flow of knowledge. Factors of the team context that can reduce this first barrier support the capability of coordination and socialization (Lowik et al., 2016). Integration and autonomy are the first two factors inherent to teamwork in coordination, focusing on horizontal communication, participation in decision making, and facilitating the flow of knowledge among members of the same team (Cohen \& Levinthal, 1990). Socialization refers to the organization's ability to establish shared ideology and values that offer employees a collective identity or interpretation of reality, that is, a state of cohesion, relative to the other factor included in this study.

\subsection{Autonomy}

The degree of operational autonomy granted to the groups refers to the intensity of the intervention from the supervision in decision making (llgen et al., 2005). In a situation of little autonomy granted to the groups, the group operators do not need to use planning, intervention or control. These activities become the responsibility of other departments, such as quality, planning and maintenance, thus forcing operators to constantly ask for support from such departments (Daspit et al., 2013). 
Operational autonomy is a desirable factor for teams, as it increases the transparency of the operational process, reduces indirect staff members, enhances communication and dialogue between individuals of the group and other sectors, and particularly encourages individuals to practice and question their knowledge and skills, promoting the creation of new knowledge (Salas et al., 2008).

Autonomy can be defined, therefore, as the amount of interdependence, initiative and freedom granted to employees for daily work-related decision making and executing (Chen et al., 2010). Autonomy gives employees individual freedom for seeking solutions to problems or for self-organizing networks of social interaction to solve these problems or even for planning and implementing improvements. Autonomy is the basis of self-organization and increases the likelihood of individuals becoming motivated to learn continuously through the creation of new knowledge and competences (Chen et al., 2010; Gonzalez et al., 2014). When the degree of autonomy is increased, managers do not specify targets, allocation of staff or lines of authority. This implies that employees start feeling more responsible for their own work and process. The organization thus encourages the creation of new ideas and knowledge, generating a more dynamic context (Chen et al., 2010). In addition, autonomy is an important condition for the collaborative leadership process in teams, as it increases the likelihood of team members to get involved in processes of mutual influence. Since dynamic capability is directly affected by the ability of individuals to make decisions within teams, the following hypotheses are stated:

$\mathrm{H} 1_{\mathrm{a}}$. Autonomy supports the knowledge absorptive capability.

$\mathrm{H} 1_{b}$. Autonomy supports the knowledge generation capability.

$\mathrm{H} 1_{\text {c }}$. Autonomy supports the knowledge storage capability.

$\mathrm{H} 1_{\mathrm{d}}$. Autonomy supports the knowledge adaptation capability.

\subsection{Cohesion}

Autonomy is more frequently observed in more cohesive and more mature groups in terms of existence (Oliveira et al., 2016; Salas et al., 2008). Shin et al. (2012), when studying the maturity of working groups, state that in immature or non-integrated groups, members have different viewpoints, work alone, often without commitment to the group, and learn on their own (Zhang \& Bartol, 2010).

In mature or integrated groups, individuals work, learn, and make decisions as a single unit, characterizing a state of high cohesion. Members of cohesive groups have a higher degree of affinity and trust, and are more satisfied and affectively attracted to the team). Cohesive teams that share tacit values and behaviors have a more solid and stable foundation for interpersonal relationships. Cohesion is developed when group members create a sense of commitment to tasks, group pride, and interpersonal attraction, that is, people like to share their moments with the other members of the group (Shin et al., 2012). The sense of cohesion increases the willingness of team members to care for and help each other and drives the learning process (Oliveira et al., 2016). In view of the role of cohesion for the development of a shared identity and unity of purpose, the following hypotheses can be stated:

$\mathrm{H} 2$ a Cohesion supports the knowledge absorptive capability.

$\mathrm{H} 2_{\mathrm{b}}$. Cohesion supports the knowledge generation capability.

$\mathrm{H} 2$. Cohesion supports the knowledge storage capability.

$\mathrm{H} 2$. Cohesion supports the knowledge adaptation capability.

\subsection{Integration}

Not every group of individuals can be considered a team, and one of the central factors that support such statement is team integration (Daspit et al., 2013). Then conflicts are common when team members with distinct skills, experiences, and interests have to perform tasks together.

If the team's internal dynamics do not support collaborative interactions among members, the team's maximum potential will not be reached (Daspit et al., 2013). Kahn (1996) proposes a team integration model based on formal (interaction) and informal (collaboration) initiatives to generate cooperation between individuals or teams. Interaction is related to formal mechanisms that integrate functions, such as meetings, exchange of documents and conferences. Collaborations refer to informal processes in which people from different departments, roles, teams or processes interact and assist each other to achieve organizational goals. Collaboration is part of an unstructured social system that includes affectivity, voluntarism, trust and willingness to share knowledge (Oliveira et al., 2016). 
Then, team integration depends on aspects related to the organizational structure, for easy communication between team members and between the team and other departments of the company, and social aspects related to the team's internal social interaction (Kahn, 1996). From these concepts, this study proposes the following hypotheses regarding the integration of teams:

$\mathrm{H}_{3}$. Integration supports the knowledge absorptive capability.

$\mathrm{H} 3 \mathrm{~b}$. Integration supports the knowledge generation capability.

$\mathrm{H} 3$. Integration supports the knowledge storage capability.

$\mathrm{H} 3{ }_{\mathrm{d}}$. Integration supports the knowledge adaptation capability.

\section{Study methodology}

\subsection{Data collection}

This study uses primary data collection to perform an empirical analysis and relate dynamic capability to contextual factors of teamwork. The questionnaire used in this study has two parts. The first part characterizes the company and the employee, and the second part addresses the contextual factors of teams and dynamic capability (refer to the Annex 1).

This study was conducted in companies that provide specialized industrial and engineering services in Brazil. In total, 390 questionnaires were emailed to employees at management and senior management levels from the departments of projects, human resources and engineering from companies that are members of the São Paulo State Industries Center (CIESP) - the list of members is available on Centro das Indústrias do Estado de São Paulo (2018) from November 2017 to February 2018. To increase the response rate, an invitation letter was sent with the questionnaire in which the researcher explains the interests and importance of the study. In addition, the research team contacted 110 companies to formalize the invitation to participate in the survey and send the questionnaire to respondents of targeted profile. A total of 188 questionnaires were sent back, which means a $48.21 \%$ response rate.

After data collection, the common method bias was evaluated using Harman's single factor test (Podsakoff et al., 2003). Based on the analysis of principal components without rotation, 23 factors were found with eigenvalues greater than 1.0, with the highest factor representing 19\% of the variance. As no single factor emerged, and no factor was responsible for most of the variance, the common bias of the method is unlikely (Podsakoff et al., 2003).

\subsection{Measurements}

The measurement variables or items of the contextual factors analyzed in this study (refer to Annex) are measured using a seven-point Likert scale, where 1 means 'never practiced or total disagreement' and 7 means 'always practiced or total agreement.' Cronbach's alpha measurement is used to estimate the reliability of measurement items. As listed below, all items presented an acceptable level of reliability, since $\alpha$ exceeded 0.7 (Hair et al., 2013). The development of measurement items was based on the following studies:

- Autonomy ( $\alpha=0.818)$ : four measurement items adapted from Gulowsen (1979) and Murakami (1997);

- Cohesion $(\alpha=0.765)$ : three measurement items adapted from Lechler (2001);

- Integration ( $\alpha=0.832)$ : three measurement items adapted from Kahn (1996);

- Absorptive capability ( $\alpha=0.768)$ : four measurement items adapted from Wang et al. (2007);

- Generation capability $(\alpha=0.781)$ : three measurement items adapted from Wang et al. (2007);

- Storage capability ( $\alpha=0.803)$ : three measurement items adapted from Wang et al. (2007);

- Adaption capability $(\alpha=0.760)$ : three measurement items adapted from Zheng et al. (2011).

\subsection{Data analysis}

Data were analyzed using partial least squares (PLS) regression. PLS is a data analysis technique of structural equation modeling (SEM) widely used in studies on management, including several studies based on organizational knowledge, dynamic capability, and KM (Gonzalez \& Melo, 2018; Gonzalez \& Melo, 2017). 
PLS can be considered an alternative to SEM, as it involves a lower level of restriction when compared to data distribution and normality, and is also more adequate when small samples are used (Hair et al., 2013). PLS is also considered appropriate for models with complex relationships. Hair et al., 2013), and for studies that intend to develop a theory based on certain constructs (Hair et al., 2013), just like this study, which aims to analyze the relationship between the contextual factors related to teamwork and dynamic capability. SmartPLS version 3.0 was used to evaluate the measurements and structural model of this study.

\section{Results and analyses}

\subsection{Description of researched companies}

This section shows the demographic characteristics of the researched companies and the descriptive statistics for research items on team cohesion, integration and autonomy. Table 1 shows demographic characteristics.

The researched companies work in the areas of maintenance-related services and support to producton. The results show that almost half of the companies operate exclusively in maintenance services. In relation to annual revenues, the results show that around $88 \%$ of the companies surveyed have annual revenues of between 16 and 300 million.

Table 1. Demographic characteristics of researched companies.

\begin{tabular}{|c|c|}
\hline Type of service & Percent $(\%)$ \\
\hline Only Maintenance & 48.94 \\
\hline Only Support to production & 21.28 \\
\hline Maintenance and Support to production & 29.79 \\
\hline \multicolumn{2}{|l|}{ Company's annual revenue (in millions of Brazilian Reals (BRL)) } \\
\hline Over BRL 300 & 11.70 \\
\hline Between 90 and 300 & 41.49 \\
\hline Between 16 and 90 & 46.81 \\
\hline \multicolumn{2}{|l|}{ Number of employees } \\
\hline Between 1500 and 4999 & 9.57 \\
\hline Between 500 and 1499 & 56.91 \\
\hline Between 100 and 499 & 33.51 \\
\hline \multicolumn{2}{|l|}{ Average number of employees allocated per client } \\
\hline Over 100 & 22.34 \\
\hline Between 70 and 99 & 29.79 \\
\hline Between 30 and 69 & 30.85 \\
\hline Lower than 30 & 17.02 \\
\hline \multicolumn{2}{|l|}{ Market time (years) } \\
\hline Over 40 & 12.23 \\
\hline Between 20 and 40 & 26.06 \\
\hline Between 10 and 20 & 37.77 \\
\hline Between 5 and 10 & 23.94 \\
\hline \multicolumn{2}{|l|}{ Respondent position in the company } \\
\hline Direction & 45.21 \\
\hline Management & 54.79 \\
\hline \multicolumn{2}{|l|}{ Respondent area of expertise } \\
\hline Service management & 32.45 \\
\hline Project & 16.49 \\
\hline Human Resources & 27.66 \\
\hline Engineering & 23.40 \\
\hline
\end{tabular}

Regarding the number of employees, there is a large concentration in the range between 500 and 1499 employees (almost 57\%), and the average number of employees allocated per client is preponderant in the range of 30 to 99 employees (60\%). Regarding the time in the market, about 38\% of companies have time between 10 and 20 years and $26 \%$ have time between 20 and 40 years. 
Despite the profile of the respondents, about 55\% occupy managerial position and 45\% directive positions. Regarding the area of action of the respondent, there were about 32\% of operation managers, $28 \%$ of professionals in the area of human resources, 23\% work in the engineering area and 17\% work in the project area.

Table 2 shows the descriptive results of the measurement items related to the constructs absorption capability, generation capability, storage capability and adaptation capacity, as well as the constructs related to teamwork (cohesion, autonomy and integration). It is verified that all the items present a factorial load superior 0.50 , as recommended by Hair et al. (2013), validating the measurement items.

Table 2. Descriptive statistics of measurement items.

\begin{tabular}{|c|c|c|c|c|}
\hline Factor & Item & Media & Standard deviation & Factor loading \\
\hline \multirow[t]{4}{*}{ Absorptive capability (Abs) } & Abs1 & 5,085 & 0.618 & 0.744 \\
\hline & Abs2 & 4,420 & 0.715 & 0.591 \\
\hline & Abs3 & 4,590 & 0.544 & 0.598 \\
\hline & Abs4 & 5,048 & 0.455 & 0.612 \\
\hline \multirow[t]{3}{*}{ Generation capability (Gen) } & Gen1 & 5,952 & 0.436 & 0.866 \\
\hline & Gen2 & 5,255 & 0.540 & 0.745 \\
\hline & Gen3 & 4,952 & 0.566 & 0.677 \\
\hline \multirow[t]{3}{*}{ Storage capability (Stor) } & Stor 1 & 6,037 & 0.356 & 0.788 \\
\hline & Stor2 & 5,388 & 0.390 & 0.637 \\
\hline & Stor3 & 5,468 & 0.378 & 0.612 \\
\hline \multirow[t]{3}{*}{ Adaption capacity (Adap) } & Adap 1 & 5,649 & 0.391 & 0.708 \\
\hline & Adap2 & 5,085 & 0.497 & 0.577 \\
\hline & Adap3 & 4,872 & 0.433 & 0.614 \\
\hline \multirow[t]{4}{*}{ Autonomy (Aut) } & Aut 1 & 5,197 & 0.648 & 0.628 \\
\hline & Aut2 & 5,048 & 0.527 & 0.775 \\
\hline & Aut3 & 4,989 & 0.541 & 0.720 \\
\hline & Aut4 & 4,936 & 0.512 & 0.788 \\
\hline \multirow[t]{3}{*}{ Cohesion (Cohe) } & Cohe1 & 5,670 & 0.448 & 0.815 \\
\hline & Cohe2 & 5,787 & 0.543 & 0.803 \\
\hline & Cohe3 & 5,271 & 0.668 & 0.672 \\
\hline \multirow[t]{3}{*}{ Integration (lnt) } & $\ln 1$ & 5,191 & 0.654 & 0.622 \\
\hline & $\ln 2$ & 5,335 & 0.702 & 0.631 \\
\hline & $\ln 13$ & 5,463 & 0.781 & 0.680 \\
\hline
\end{tabular}

\subsection{Convergent and discriminant validity}

First, this study evaluates the psychometric properties of the measurement scale in terms of reliability, convergent validity and discriminant validity, using the procedure of confirmatory factor analysis (CFA) (Hair et al., 2013). The reliability of the items can be attested using Cronbach's alpha measurements and construct reliability (CR). All Cronbach's alpha values were acceptable, that is, higher than 0.70, as indicated above. Table 3 shows $\mathrm{CR}$ and factor loading values. The CR values of the constructs are greater than 0.70 , indicating the presence of convergent validity and reliability of the constructs, that is, the variables that constitute the constructs present common variance. Besides, the values of factor loading of the items on their constructs are greater than 0.60 and the AVE values are greater than 0.50.

The values of average variance extracted (AVE) of the constructs confirm the presence of discriminant validity, that is, the constructs are different from one another. In Table 4, the values outside the diagonal indicate the correlations between the constructs, and the diagonal refers to the square root of AVE values of each construct. Note that the square root values of AVEs for each construct are greater than the correlation with the other constructs, indicating the presence of discriminant validity.

\subsection{Structural model and hypothesis testing}

The goodness-of-fit (GoF) index of the model and the $\mathrm{R}^{2}$ value of endogenous (dependent) variables are measurements that validate the PLS model, evaluating the consistency of the measurement scale and the structural model. The GoF determines the overall predictive power of the model, considering the parameters 


\begin{tabular}{|c|c|c|c|c|}
\hline Factor & Item & Factor loading & CR & AVE \\
\hline \multirow[t]{4}{*}{ Absorptive capability (Abs) } & Abs1 & 0.802 & \multirow{4}{*}{0.815} & \multirow{4}{*}{0.673} \\
\hline & Abs2 & 0.775 & & \\
\hline & Abs3 & 0.778 & & \\
\hline & Abs4 & 0.793 & & \\
\hline \multirow[t]{3}{*}{ Generation capability (Gen) } & Gen 1 & 0.826 & \multirow{3}{*}{0.826} & \multirow{3}{*}{0.698} \\
\hline & Gen2 & 0.791 & & \\
\hline & Gen3 & 0.750 & & \\
\hline \multirow[t]{3}{*}{ Storage capability (Stor) } & Stor 1 & 0.815 & \multirow{3}{*}{0.788} & \multirow{3}{*}{0.705} \\
\hline & Stor2 & 0.828 & & \\
\hline & Stor3 & 0.788 & & \\
\hline \multirow[t]{3}{*}{ Adaption capacity (Adap) } & Adap 1 & 0.734 & \multirow{3}{*}{0.761} & \multirow{3}{*}{0.680} \\
\hline & Adap2 & 0.771 & & \\
\hline & Adap3 & 0.809 & & \\
\hline \multirow[t]{4}{*}{ Autonomy (Aut) } & Aut1 & 0.875 & \multirow{4}{*}{0.790} & \multirow{4}{*}{0.783} \\
\hline & Aut2 & 0.813 & & \\
\hline & Aut3 & 0.780 & & \\
\hline & Aut4 & 0.833 & & \\
\hline \multirow[t]{3}{*}{ Cohesion (Cohe) } & Cohe1 & 0.761 & \multirow{3}{*}{0.777} & \multirow{3}{*}{0.756} \\
\hline & Cohe2 & 0.720 & & \\
\hline & Cohe3 & 0.782 & & \\
\hline \multirow[t]{3}{*}{ Integration (Int) } & $\operatorname{lnt} 1$ & 0.867 & \multirow{3}{*}{0.836} & \multirow{3}{*}{0.795} \\
\hline & lnt2 & 0.888 & & \\
\hline & $\operatorname{lnt} 3$ & 0.778 & & \\
\hline
\end{tabular}

Table 4. Discriminant validity.

\begin{tabular}{|c|c|c|c|c|c|c|c|}
\hline Factor & Abs & Gen & Stor & Adap & Aut & Cohe & $\operatorname{lnt}$ \\
\hline Abs & 0.820 & & & & & & \\
\hline Gen & 0.433 & 0.835 & & & & & \\
\hline Stor & 0.238 & 0.288 & 0.840 & & & & \\
\hline Adap & 0.291 & 0.356 & 0.273 & 0.825 & & & \\
\hline Aut & 0.195 & 0.285 & 0.166 & 0.272 & 0.885 & & \\
\hline Cohe & 0.178 & 0.221 & 0.098 & 0.255 & 0.236 & 0.869 & \\
\hline $\ln t$ & 0.205 & 0.333 & 0.151 & 0.281 & 0.242 & 0.347 & 0.892 \\
\hline
\end{tabular}

Note: The values of diagonal cells refer to the square root values of AVE.

of the measurement scale and structure (Hair et al., 2013). The GoF found for the model of this study is 0.38 , exceeding the cutoff value of 0.290 for large effects of $\mathrm{R}^{2}$ suggested by Hair et al. (2013), indicating the model presents excellent predictive power.

Path coefficients in the PLS model are similar to $\beta$ coefficients from the regression analysis (Hair et al., 2013). Table 5 present the results for the structural model. The $\mathrm{R}^{2}$ value indicates the predictive power of the model and the ability of the independent variables to explain the dependent variables. The values found for $\mathrm{R}^{2}$ were 0.30 for absorptive capability; 0.36 for generation capability; 0.44 for storage capability; and 0.32 for adaptation capability. These results are acceptable for an exploratory study (Hair et al., 2013).

Cohesion was the only factor that presented all the statistically positive and significant relations with standardized path coefficient (SPC) of 0.240 ( $p<0.01), 0.391$ ( $p<0.001), 0.293(p<0.0001)$ and $0.355(p<0.0001)$ in relation to the absorption capability, generation capability, storage capability and adaptation capability, respectively. The autonomy factor presented a statistically significant and positive relation with the knowledge absorption caability ( $\mathrm{SPC}=0.245, \mathrm{p}<0.01)$, with the knowledge generation capability $(\mathrm{SPC}=0.332, \mathrm{p}<0.001)$ and with the knowledge adaptation capability (SPC $=0.239, \mathrm{p}<0.01$ ). Autonomy did not present a statistically significant relation with knowledge storage capability. Finally, the integration factor presented a statistically positive and significant relation with knowledge generation capability $(S P C=0.405, p<0.001)$, knowledge storage capability $(S P C=0.305, p<0.001)$ and knowledge adaptation capability $(S P C=0.233, p<0.01)$. The integration did not present a statistically significant relation with the knowledge absorption capability. 


\begin{tabular}{|c|c|c|c|}
\hline Path & Path coefficient & t-value & Result \\
\hline H1a: Autonomy $\rightarrow$ Abs & $0.245^{*}$ & 3.658 & Accepted \\
\hline H1b: Autonomy $\rightarrow$ Gen & $0.332^{* *}$ & 4.890 & Accepted \\
\hline H1c: Autonomy $\rightarrow$ Stor & 0.115 & 1.291 & Rejected \\
\hline H1d: Autonomy $\rightarrow$ Adap & $0.239^{*}$ & 3.542 & Accepted \\
\hline H2a: Integration $\rightarrow$ Abs & 0.118 & 1.302 & Rejected \\
\hline H2b: Integration $\rightarrow$ Gen & $0.405^{* *}$ & 6.444 & Accepted \\
\hline H2c: Integration $\rightarrow$ Stor & $0.305^{* *}$ & 4.562 & Accepted \\
\hline H2d: Integration $\rightarrow$ Adap & $0.233^{*}$ & 3.466 & Accepted \\
\hline H3a: Coheson $\rightarrow$ Abs & $0.240^{*}$ & 3.602 & Accepted \\
\hline H3b: Cohesion $\rightarrow$ Gen & $0.391^{* *}$ & 6.223 & Accepted \\
\hline H3c: Cohesion $\rightarrow$ Stor & $0.293^{* *}$ & 4.239 & Accepted \\
\hline H3d: Cohesion $\rightarrow$ Adap & $0.355^{* *}$ & 5.534 & Accepted \\
\hline
\end{tabular}

Note: ${ }^{*} p<0.05 ;{ }^{* *} p<0.01$.

\section{Discussion and conclusions}

This study was developed in order to investigate how the dynamic capability is affected by the intrinsic characteristics of teamwork in the context of companies that provide specialized industrial services. The literature points to a close relationship between contextual factors of the organization, such as organizational culture, leadership style, human resources development and organizational structure, on dynamic capability (Zheng et al., 2011; Gonzalez \& Melo, 2018). However, the literature on the subject is lacking in research that assesses dynamic capability in teamwork. In this way, the results of this study extend and deepen the understanding of dynamic capability in the context of multi-unit teamwork.

The model presents new results in relation to the current literature. The main highlight is the importance of the cohesion state of the team for the success of all the processes related to the dynamic capability, demonstrated by the high values of the standardized coefficients.

Analyzing the context in which the study was carried out, companies that providing specialized industrial service in multi-unit, it is possible to verify groups of employees that work within the clients, that is, away from their headquarters companies. In this sense, unity of purpose, shared identity and mutual trust among team members becomes essential for the processes of absorption, generation, storage and adaptation of knowledge. This result is in line with the works Donate \& Guadamillas (2011) and Singh \& Rao (2016) that emphasize that in cohesive teams, the construction of a stock of primary knowledge and a common language facilitate in particular the processes of absorption, generation and adaptation of knowledge. In addition, the common language among individuals in cohesive groups facilitates the process of retrieval and dissemination of tacit knowledge, as well as the explanation of this knowledge.

The results of the study on cohesion and dynamic capability are in line with the findings of Lee (2018) and Teece et al. (2016) that propose that the innovative process and the dynamic capability are better supported by the tacit knowledge than by the explicit knowledge, since the tacit knowledge is the one that guarantees hardly imitable and shared advantage.

Due to the association between tacit knowledge flow and cohesion, it is possible to conclude that cohesion is a variable present in the teams that best supports the dynamic capability. The results of the model corroborate this importance through the high standardized coefficients.

The integration of the team showed positive relations with the processes of generation, storage and adaptation of knowledge, in contrast, did not present significant relation with the absorption of knowledge. This result points out that the knowledge flow between individuals supports the treatment and processing of the knowledge already acquired and dominated by the team, regarding the creation, modification and retrieval of this knowledge. Cooperation among individuals and the flow of knowledge inherent in integrated teams, in turn, do not allow the absorption of new knowledge.

In this way, this research points out that the integration between teams' functional areas is directly related to incremental dynamic capability, that is, the one that uses the same primary knowledge base. In relation to the radical innovative capacity, which presupposes the absorption and creation of new knowledge, the integration does not present significant relation. The results of the studies show that integration is more strongly related to knowledge generation and storage processes. This result indicates that much of the knowledge influenced by team integration refers to explicit knowledge (more easily stored), corroborating the condition of incremental dynamic and innovative capability. 
Autonomy presented a significant and positive relation with the processes of absorption, generation and adaptation of knowledge. Similar to the results found by Daspit et al. (2013), decentralization in decision-making promotes the creative process, supporting the generation and adaptation of knowledge in other applications. In the context of multi-unit service provision, this result is fairly consistent as teams work far from their headquarters and thus individuals must make rapid decisions in order to solve problems and promote improvements, which lead to increased performance, generating and adapting knowledge. In addition, the allocation of teams within the clients places the individuals of the service company in direct contact with the processes, problems and knowledge retained by the clients. In this sense, team employees need autonomy to identify, select, and absorb the client's knowledge in order to modify or adapt it.

However, autonomy did not present a significant relationship with the knowledge storage process. Again, the context of the work of service teams helps to explain this result. In line with Lee et al. (2015), the teams of the service provider have greater responsibility for the improvement and correction of the processes of the clients. According to Gonzalez et al. (2014), the storage of knowledge in multi-unit service processes is performed by employees who work at the headquarters of the service provider in centers of excellence, which retrieve best practices and lessons from the teams inserted in the clients.

\subsection{Managerial Implications}

This study offers a number of important insights for practioners willing to nurture or develop dynamic capability in teamworks. The development of contextual factors of teams, such as cohesion, integration and autonomy, is a critical factor for dynamic capability, especially when it comes to companies that provide service in the multi-unit system.

It is not uncommon, in the context of multi-unit service provision, that employees of teams allocated full time on different clients miss cultural values of the company they work in, identifying themselves more directly with the values of the client company. In this way, this work presented the form with the three aspects of the teams impact the dynamic and, consequently, innovative capacity of companies providing industrial services.

It is recommended that service site managers develop teams with a cohesive state, in what concerns the creation of a shared identity and language amng individuals and a sense of collective overlapping the individual. Cohesion is the only factor included in the study that presented significant relationships for all processes related to the dynamic capability (absorption, generation, storage and adaptation), in addition to present stronger relationships with these processes. In particular, in terms of processes of knowledge absorption and adaptation, i.e., processes more related to the use of tacit knowledge, cohesion was more significant.

Given that teams work with clients, far from the service provider, it is essential to offer these teams autonomy for problem solving and for improvements. Working in partnership with the employees of the client companies promotes the absorption of new knowledge. In this context, the service provider must build an integrative environment in order to absorb and modify knowledge generated in conjunction with client companies. In addition, the service provider acts as an integrator of knowledge by retaining it and distributing it among other service service provision teams.

\subsection{Limitations and direction for future studies}

The results of this study should be considered with some limitations. The first refers to reduced sample size. Future studies may consider working with a larger number of service providers.

The authors chose to study dynamic capability in teams from multi-unit specialized industrial service companies. This context is very peculiar, since the service provision teams are created and assigned to customers' sites, reducing the degree of interaction between team members and staff of the service company. This way, contextual factors such as organizational culture, organizational structure and organizational climate, can be affected by distance. A future study may compare dynamic capability in teams working in the context analyzed in this study to teams that work closer to the service company.

Another limitation concerns the factors included in the study. In this study, we chose to use three factors related to team cohesion, integration and autonomy. Other contextual factors can be studied in future works such as mutual trust, shared language, team organizational structure and human resource development.

\section{Acknowledgements}

The author thanks São Paulo Research Foundation - FAPESP (2016/24401) for the financial support. 


\section{References}

Alavi, M., \& Leidner, D. E. (2001). Knowledge Management and Knowledge Management Systems: conceptual Foundations and Research Issues. Management Information Systems Quarterly, 25(1), 107-136. http://dx.doi.org/10.2307/3250961.

Argyris, C., \& Schön, D. Organizational Learning. A theory of action perspective. Boston: Addison-Wesley, 1978.

Centro das Indústrias do Estado de São Paulo (2018). Cadastro Industrial do Estado de São Paulo. Retrieved in 2018, January 10, from Available from: https://ebgebrasil.com.br/industrias/sp/cadastro-industrial/categorias/

Chen, C. J., Huang, J. W., \& Hsiao, Y. C. (2010). Knowledge management and innovativeness: The role of organizational climate and structure. International Journal of Manpower, 31(8), 848-870. http://dx.doi.org/10.1108/01437721011088548.

Cohen, W. M., \& Levinthal, D. (1990). Absorptive capacity: a new perspective on learning and innovation. Administrative Science Quarterly, 35(1), 128-152. http://dx.doi.org/10.2307/2393553.

Daspit, J., Tillman, C. J., Boud, N. G., \& Mckee, V. (2013). Cross-functional team effectiveness: an examination of internal team environment, shared leadership, and cohesion influences. Team Performance Management, 19(1), 34-56. http://dx.doi.org/10.1108/13527591311312088.

Denford, J. S. (2013). Building knowledge: developing a knowledge-based dynamic capabilities typology. Journal of Knowledge Management, 17(2), 175-194. http://dx.doi.org/10.1108/13673271311315150.

Donate, M. J., \& Guadamillas, F. (2011). Organizational factors to support knowledge management and innovation. Journal of Knowledge Management, 15(6), 890-914. http://dx.doi.org/10.1108/13673271111179271.

Eisenhardt, K. M., \& Martin, J. A. (2000). Dynamic capabilities: what are they? Strategic Management Journal, 21(10-11), 1105-1121. http://dx.doi.org/10.1002/1097-0266(200010/11)21:10/11<1105::AID-SMJ133>3.0.C0;2-E.

Gonzalez, R. V. D. (2017). Knowledge exploration and exploitation in team context. Total Quality Management \& Business Excellence, 41(4), 1-21. http://dx.doi.org/10.1080/14783363.2017.1400377.

Gonzalez, R. V. D., \& Melo, T. M. (2017). Linkage between dynamics capability and knowledge management factors: A structural equation model. Management Decision, 55(10), 2256-2276. http://dx.doi.org/10.1108/MD-03-2017-0180.

Gonzalez, R. V. D., \& Melo, T. M. (2018). The effects of organization context on knowledge exploration and exploitation. Journal of Business Research, 90, 215-225. http://dx.doi.org/10.1016/j.jbusres.2018.05.025.

Gonzalez, R. V. D., Martins, M. F., \& Toledo, J. C. (2014). Managing knowledge in a service provider: a network structure-based model. Journal of Knowledge Management, 18(3), 611-630. http://dx.doi.org/10.1108/JKM-12-2013-0502.

Grant, R. M. (1996). Toward a knowledge-based theory of the firm. Strategic Management Journal, 17(S2), 109-122. http://dx.doi. org/10.1002/smj.4250171110.

Gulowsen, J. (1979). A measure of work-group-autonomy. In L. E. Davis \& J. C. Taylor (Eds.), Design of jobs (2nd ed., pp. 206-218). Santa Monica: Goodyear.

Gutierrez, L. J. G., Molina, V. B., \& Kaynak, H. (2018). The role of human resource-related quality management practices in new product development: A dynamic capability perspective. International Journal of Operations \& Production Management, 38(1), 43-66. http:// dx.doi.org/10.1108/1JOPM-07-2016-0387.

Hair, J. F., Hult, G. T. M., Ringle, C., \& Sarstedt, M. (2013). A primer on partial least squares structural equation modeling (PLS-SEM). London: Sage Publications Ltd.

Han, Y., \& Li, D. (2015). Effects of intellectual capital on innovative performance: The role of knowledge-based dynamic capability. Management Decision, 53(1), 40-56. http://dx.doi.org/10.1108/MD-08-2013-0411.

Hitt, M., Xu, K., \& Carnes, C. (2016). Resource based theory in operations management research. Journal of Operations Management, 41(1), 77-94. http://dx.doi.org/10.1016/j.jom.2015.11.002.

Ilgen, D. R., Hollenbeck, J. R., Johnson, M., \& Jundt, D. (2005). Team in organizations: from input-process-output models to IM01 models. Annual Review of Psychology, 56(1), 517-543. http://dx.doi.org/10.1146/annurev.psych.56.091103.070250. PMid:15709945.

Jaca, C., Viles, E., Tanco, M., Mateo, R., \& Santos, J. (2013). Teamwork effectiveness factors in healthcare and manufacturing industries. Team Performance Management, 19(3/4), 222-236. http://dx.doi.org/10.1108/TPM-06-2012-0017.

Jones, A. B., \& Knoppen, D. (2018). The role of strategic purchasing in dynamic capability development and deployment: A contingency perspective. International Journal of Operations \& Production Management, 38(2), 446-473. http://dx.doi.org/10.1108/ IJOPM-10-2015-0656.

Kahn, K. B. (1996). Interdepartmental integration: a definition with implications for product development performance. Journal of Product Innovation Management, 13(2), 137-151. http://dx.doi.org/10.1016/0737-6782(95)00110-7.

Kozlowski, S. W. J., \& llgen, D. R. (2006). Enhancing the effectiveness of work groups and teams. Psychological Science in the Public Interest, 7(3), 77-124. http://dx.doi.org/10.1111/j.1529-1006.2006.00030.x. PMid:26158912.

Lechler, T. (2001). Social interaction: a determinant of entrepreneurial team venture success. Small Business Economics, 16(4), 263-278. http://dx.doi.org/10.1023/A:1011167519304.

Lee, P. Y. (2018). How to develop dynamic capabilities in multiunits: The roles of international experience and career capital. Management Decision, 56(2), 344-357. http://dx.doi.org/10.1108/MD-11-2016-0854.

Lee, P. Y., Kung, C. Y., \& Li, C. S. J. (2015). Developing dynamic capabilities in culturally distant service multi-units. Industrial Management \& Data Systems, 115(8), 1547-1562. http://dx.doi.org/10.1108/IMDS-01-2015-0025.

Lowik, S., Kraaijenbrink, J., \& Groen, A. (2016). The team absorptive capacity triad: a configurational study of individual, enabling, and motivating factors. Journal of Knowledge Management, 20(5), 1083-1103. http://dx.doi.org/10.1108/JKM-11-2015-0433

Mathieu, J., Maynard, M. T., Rapp, T., \& Gilson, L. (2008). Team effectiveness 1997-2007: a review of recent advancements and a glimpse into the future. Journal of Management, 34(3), 410-476. http://dx.doi.org/10.1177/0149206308316061.

Murakami, T. (1997). The autonomy of teams in the car industry - a cross national comparison. Work, Employment and Society, 11(4), 749-758. 
0'Reilly, C. A. 3rd, \& Tushman, M. L. (2008). Ambidexterity as a dynamic capability: resolving the innovator's dilemma. Research in Organizational Behavior, 28, 185-206. http://dx.doi.org/10.1016/j.riob.2008.06.002.

Oliveira, E. A., Pimenta, M. L., Hilletofth, P., \& Eriksson, D. (2016). Integration through cross-functional teams in a service company. European Business Review, 28(4), 405-430. http://dx.doi.org/10.1108/EBR-01-2016-0014.

Podsakoff, P. M., MacKenzie, S. B., Lee, J. Y., \& Podsakoff, N. P. (2003). Common method biases in behavioral research: a critical review of the literature and recommended remedies. The Journal of Applied Psychology, 88(5), 879-903. http://dx.doi.org/10.1037/00219010.88.5.879. PMid:14516251.

Salas, E., Cooke, N. J., \& Rosen, M. A. (2008). On teams, teamwork, and team performance: discoveries and developments. Human Factors, 50(3), 540-547. http://dx.doi.org/10.1518/001872008X288457. PMid:18689065.

Shin, S. J., Kim, T. Y., Lee, J. Y., \& Bian, L. (2012). Cognitive team diversity and individual team member creativity: A cross-level interaction. Academy of Management Journal, 55(1), 197-212. http://dx.doi.org/10.5465/amj.2010.0270.

Singh, B., \& Rao, M. K. (2016). Effect of intellectual capital on dynamic capabilities. Journal of Organizational Change Management, 29(2), 129-149. http://dx.doi.org/10.1108/J0CM-12-2014-0225.

Teece, D. J., Peteraf, M., \& Leih, S. (2016). Dynamic capabilities and organizational agility. California Management Review, 58(4), 1335. http://dx.doi.org/10.1525/cmr.2016.58.4.13.

Teece, D. J., Pisano, G., \& Shuen, A. (1997). Dynamic capabilities and strategic management. Strategic Management Journal, 18(7), 509-533. http://dx.doi.org/10.1002/(SICl)1097-0266(199708)18:7<509::AlD-SMJ882>3.0.CO;2-Z.

Walsh, J. P., \& Ungson, G. R. (1991). Organizational Memory. Academy of Management Review, 16(1), 57-91. http://dx.doi.org/10.5465/ amr.1991.4278992.

Wang, E., Klein, G., \& Jiang, J. J. (2007). IT support in manufacturing firms for a knowledge management dynamic capability link to performance. International Journal of Production Research, 45(11), 2419-2434. http://dx.doi.org/10.1080/00207540601020437.

Wilden, R., \& Gudergan, S. (2017). Service-dominant orientation, dynamic capabilities and firm performance. Journal of Service Theory and Practice, 27(4), 808-832. http://dx.doi.org/10.1108/JSTP-04-2016-0077.

Zahra, S. A., \& George, G. (2002). Absorptive capacity: a review, reconceptualization, and extension. Academy of Management Review, 27(2), 185-203. http://dx.doi.org/10.5465/amr.2002.6587995.

Zhang, X. M., \& Bartol, K. M. (2010). Linking empowering leadership and employee creativity: the influence of psychological empowerment, intrinsic motivation, and creative process engagement. Academy of Management Journal, 53(1), 107-128. http:// dx.doi.org/10.5465/amj.2010.48037118.

Zheng, S., Zhang, W., \& Du, J. (2011). Knowledge-based dynamic capabilities and innovation in networked environments. Journal of Knowledge Management, 15(6), 1035-1051. http://dx.doi.org/10.1108/13673271111179352.

Zollo, M., \& Winter, S. G. (2002). Deliberate learning and the evolution of dynamic capabilities. Organization Science, 13(3), 339-351. http://dx.doi.org/10.1287/orsc.13.3.339.2780. 
Annex 1 - Measurement items

1. Dynamic capability

- Absorptive capability

Abs1. My company absorbs new knowledge originated by suppliers, the competition and customers.

Abs2. My company absorbs new knowledge originated from patents.

Abs3. My company absorbs new knowledge originated by research institutes.

Abs4. My company absorbs new knowledge originated by new employees.

- Generation capability

Gen 1 . New knowledge is generated internally through individual learning.

Gen2. My company performs research \& development activities that generate new knowledge.

Gen3. My company builds strategic alliances with other companies and institutes that promote internal generation of new knowledge.

- Storage capability

Stor1. Generated and absorbed knowledge is stored in documents.

Stor2. Stored knowledge is easily interpreted and used by individuals.

Stor3. Stored knowledge is disseminated among individuals.

- Adaption capability

Adap1. Individuals apply knowledge generated from different learning processes.

Adap2. My company favors knowledge integration from different segments, individuals and teams.

Adapt3. My company combines prior knowledge with new knowledge that has been created or absorbed.

\section{Autonomy}

Aut1. Team members have influence on the process of activity planning.

Aut2. Team members have influence on the process of task distribution among members.

Aut3. Team members have influence on the formulation process of work-related goals.

Aut4. Team members have power to make operational decisions.

\section{Cohesion}

Cohe1. Mutual trust among the members is a characteristic of the team.

Cohe2. Team members are committed to common goals and objectives.

Cohe3. Team members have a shared identity.

\section{Integration}

Int 1 . The team structure facilitates cooperation among members.

Int2. The team structure promotes communication and exchange of knowledge between members.

Int3. The team structure allows fast responses to market changes. 